\title{
Effectiveness of sequential v. standard triple therapy for treatment of Helicobacter pylori infection in children in Nairobi, Kenya
}

\author{
A Laving, ${ }^{1,2}$ MMed; R Kamenwa, ${ }^{2}$ MMed; S Sayed, ${ }^{3}$ MMed; A N Kimang'a, ${ }^{4}$ PhD; G Revathi, ${ }^{3}$ MMed \\ ${ }^{1}$ Department of Paediatrics and Child Health, University of Nairobi, Kenya \\ ${ }^{2}$ Department of Paediatrics and Child Health, Aga Khan University Hospital, Nairobi, Kenya \\ ${ }^{3}$ Department of Pathology, Aga Khan University Hospital, Nairobi, Kenya \\ ${ }^{4}$ Department of Medical Microbiology, Jomo Kenyatta University of Agriculture and Technology, Nairobi, Kenya
}

Corresponding author: A Laving (arlaving@yahoo.com)

Background. Once the diagnosis of Helicobacter pylori is confirmed, treatment requires at least two antibiotics and an acid inhibitor for a minimum of seven days. Unfortunately, treatment failures are being frequently reported. Treatment regimens that include sequential administration of antibiotics with acid inhibitors have been developed to try and increase the rate of eradication.

Objective. To determine the effectiveness of a novel 10-day sequential therapy compared with the standard 10-day triple therapy for treatment of $H$. pylori infection in children.

Methods. A double-blinded, randomised, controlled trial was conducted. Children under the age of 16 years with recurrent abdominal pain associated with dyspepsia and diagnosed with $H$. pylori by histology were randomly allocated either to a 10 -day sequential treatment regimen or to a 10-day conventional triple therapy. Analysis of the outcome of this study was based on clinical improvement and confirmed $H$. pylori eradication based on stool $H$. pylori antigen detection and/or repeat endoscopy.

Results. Of the 71 patients included in the analysis, 45 (63.4\%) were given the 10-day conventional treatment while $26(36.6 \%)$ received the 10 -day sequential treatment. There was no difference in clinical improvement after treatment in the two therapies. However, there was a significant difference in the eradication of $H$. pylori between the conventional v. sequential regimens $(48.8 \%$ v. $84.6 \%$, respectively; $p=0.02$, odds ratio 0.19).

Conclusion. The sequential treatment had a significantly higher $H$. pylori eradication rate than the conventional treatment.

S Afr Med J 2013;103(12):921-924. DOI:10.796/SAMJ.7012

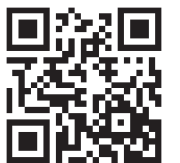

Helicobacter pylori are Gram-negative, spiral, flagellate bacilli that cause acute and chronic gastritis and peptic ulcer disease in both children and adults. ${ }^{[1]} \mathrm{H}$. pylori was first isolated in 1983 by Warren and Marshal. ${ }^{[2]}$ This discovery was a major breakthrough in the management of dyspepsia. ${ }^{[3]}$ The organism has also been recognised as a class 1 gastric carcinogen and infection at a younger age is thought to increase the risk of developing gastric cancer. ${ }^{[4]}$ Children are infected with $H$. pylori at a much younger age in developing countries, some of which report higher rates of gastric cancer. ${ }^{[5]}$

The prevalence of $H$. pylori infection varies from $20 \%$ to $50 \%$ in industrialised countries, ${ }^{[6]}$ while studies have shown that the prevalence is high in regions of Africa and Asia. Therapy can be complicated by various factors including drug costs and availability, treatment side-effects, and the presence of bacterial strains that are antibiotic resistant. ${ }^{[7]}$

Antibiotic resistance is an ever-increasing problem in the treatment of most microbial infections including $H$. pylori. The widespread and sometimes indiscriminate use of antibiotics in developing countries has resulted in a higher prevalence of resistance than in industrialised countries. ${ }^{[8]}$ New antimicrobial agents are being developed to overcome the problem of antibiotic resistance in bacterial pathogens, such as a combination of antibiotics with plant extract and other natural products that possess antimicrobial activity. ${ }^{[9]}$ The standard and most recommended treatment for the eradication of $H$. pylori, in all international guidelines, is triple therapy using a combination of two antibiotics (clarithromycin plus amoxicillin or metronidazole) and a proton pump inhibitor (PPI) for at least 7 days. ${ }^{[10]}$ However, a recent meta-analysis that included over 53000 patients showed that the eradication rate after a standard triple treatment is currently below $80 \% .{ }^{[1]]}$ Thus eradication is not achieved in at least $1 / 5$ patients, prompting research on sequential therapy.

A novel 10-day sequential treatment regimen comprising a PPI and amoxicillin double therapy for 5 days followed by a PPI, clarithromycin and tinidazole triple therapy for a further 5 days has been shown to achieve $H$. pylori eradication rates of $95 \%$ and $97 \%$ in European adults and children, respectively. This regimen, compared with the conventional triple therapy, improved eradication rates by $18 \%$ and $22 \%$, respectively, was well tolerated, safe and had good compliance in both adults and children. ${ }^{[12,13]}$

Local data on eradication rates are not available but anecdotal evidence suggests that there are increasing failure rates to the standard triple therapy regimens.

\section{Objective}

To establish whether there was any difference in the treatment of $H$. pylori infection using the 10-day sequential therapy v. the 10-day conventional triple therapy, based on clinical improvement of the patients and $H$. pylori eradication. 


\section{Methods \\ Study design}

A double-blinded, randomised, controlled trial was conducted on children under the age of 16 years.

\section{Study setting and participants}

The study was carried out at the Paediatric Gastroenterology Clinic, Aga Khan University Hospital, Kenya between March 2007 and October 2007. Children under the age of 16 years presenting with recurrent abdominal pain (defined as abdominal pain present for at least three months) associated with dyspepsia (pain or discomfort in the upper abdomen) and diagnosed with $H$. pylori by histology were recruited from the clinic on a consecutive basis. Children previously treated for $H$. pylori infection, those who had taken any antibiotic, PPI or $\mathrm{H} 2$ receptor antagonist 4 weeks prior to the study, and children with known allergies to antibiotics, were excluded.

Permission for this study was granted by the Aga Khan University Hospital Research and Ethics Committee. Informed consent was obtained from the patients or caregivers prior to recruitment. All interviews were carried out in private and all records were accessible only to the investigators.

\section{Data collection}

An upper endoscopy was done on all children with recurrent abdominal pain and dyspepsia using the standard paediatric gastroscope under deep sedation with propofol administered by an anaesthetist, and the endoscopy findings were documented. Two biopsy specimens each from gastric antrum and body were obtained and placed in $10 \%$ buffered formalin for histopathology. All sections were Giemsa stained to detect H. pylori. Inflammation, activity and other mucosal alterations such as gland atrophy and intestinal metaplasia were evaluated semiquantitatively, based on the Sidney system, by the study histopathologist. Patients returned to the clinic a week after the endoscopy examination. Those with a positive $H$. pylori test on histology were recruited consecutively and a structured questionnaire was administered to obtain detailed information on their clinical symptoms. Participants were then referred to the pharmacy where an independent pharmacist randomised patients to either the 10-day sequential treatment or the 10-day conventional treatment. A computer programme was used to generate random numbers to assign patients to either of the two arms as they were recruited. Both the study physicians and the patients were therefore blinded. A total of 104 patients were recruited with 52 receiving sequential treatment while 52 were allocated to the standard triple therapy arm (Fig. 1).

The 10-day sequential therapy included $1 \mathrm{mg} / \mathrm{kg} /$ day omeprazole plus $50 \mathrm{mg} / \mathrm{kg} /$ day amoxicillin for 5 days followed by $1 \mathrm{mg} / \mathrm{kg} /$ day omeprazole plus $15 \mathrm{mg} / \mathrm{kg} /$ day clarithromycin plus $20 \mathrm{mg} / \mathrm{kg} /$ day tinidazole for the next 5 days. The 10-day conventional triple therapy consisted of $1 \mathrm{mg} / \mathrm{kg} /$ day omeprazole plus $50 \mathrm{mg} / \mathrm{kg} /$ day amoxicillin plus $15 \mathrm{mg} / \mathrm{kg} /$ day clarithromycin for 10 days.

\section{Follow-up}

The patients were asked to return at the end of the treatment period (two weeks) so as to assess compliance and evaluate any adverse events. The child's parents/guardians were questioned regarding compliance with medication schedules. There were no noncompliance issues. After six weeks patients were seen as part of routine practice to assess possible persistence of symptoms and to undergo a follow-up physical examination. The outcome of the treatment was based on both clinical improvement and whether $H$. pylori was eradicated. The eradication was determined by use of a stool antigen test and/or a repeat histology obtained at repeat endoscopy.

\section{Statistical analysis}

$\chi^{2}$ analysis was performed to assess differences in both treatment regimes, with $p<0.05$ being considered significant. Frequencies for age and sex of the participants were also analysed. Analysis was based on both clinical improvement and H. pylori eradication.

\section{Results}

Equal numbers of patients were initially recruited in both arms of treatment. Although the majority of patients in the sequential v. conventional treatment groups ( $n=41 ; 79 \% \quad$ v. $n=49 ; 94 \%$, respectively) were seen at the six-week follow-up visit, only $26(63 \%)$ of those in the sequential arm underwent confirmation of $H$. pylori eradication v. $45(92 \%)$ in the conventional therapy arm.

A total of 71 children who were followed up to the six weeks were included in this study. The male to female ratio was 1.15:1. The ages of these children varied from 2 to 16 years with a mean age of 8.9 years (standard deviation (SD) \pm 3.096 ). Final analysis was done on 45 patients $(63.4 \%)$ in the conventional treatment arm and 26 $(36.6 \%)$ in the sequential treatment arm (Table 1). There were more males than females (53.5\% and $46.5 \%$, respectively) and just more than a third of the patients were $>8$ years of age. In total, 45/71 (63.4\%) patients received conventional therapy while 26 (36.6\%) were given sequential treatment.

After randomisation, the group that received the conventional therapy had a mean age of 9.1 years (SD \pm 3.11 ; standard error (SE) \pm 0.46 ) The sequential therapy group had a mean age of 8.81 years ( $\mathrm{SD} \pm 3.12$; $\mathrm{SE} \pm 0.61)$. The other

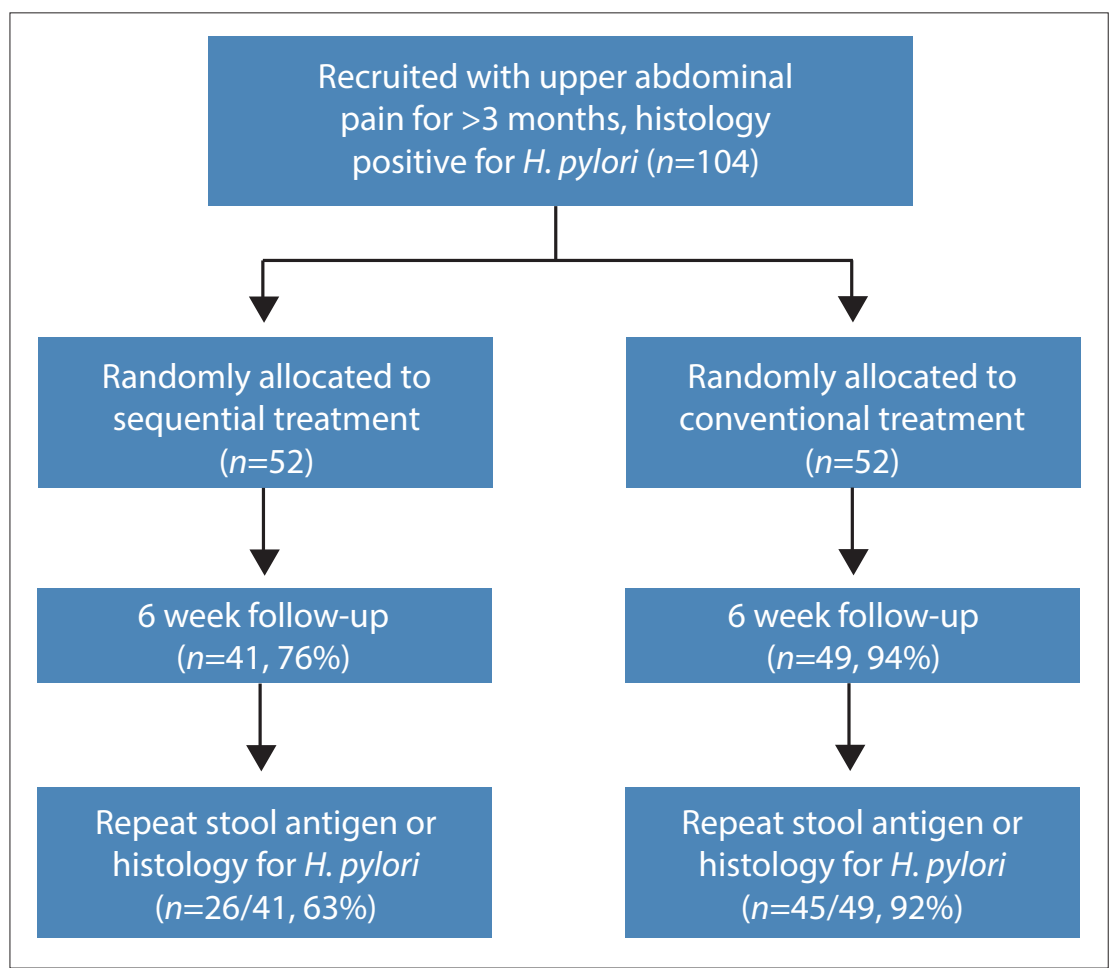

Fig. 1. Study flow diagram. 
demographic factors analysed are shown in Table 2. Although the gender ratio was similar in the two groups, there were more children in the 8 - 11-year and fewer children in the 12 - 16-year age categories in the sequential group $v$. the conventional group.

Clinical improvement was observed in $88.7 \%$ of patients after treatment, while eight $(11.3 \%)$ did not show improvement. Forty patients (88.9\%) in the conventional treatment arm showed clinical improvement v. $23(88.5 \%)$ of those in the sequential treatment arm. There was no significant difference in clinical improvement between the two regimens ( $p=0.95$; odds ratio (OR) 1.04). Neither gender $(p=0.19)$ nor age $(p=0.79)$ of the participants was significantly associated with clinical improvement (Table 3 ). Clinical improvement (resolution of dyspeptic symptoms) was seen in almost $90 \%$ in both treatment groups. Neither age nor sex differences were noted in the two groups.

Of the 71 patients, H. pylori was eradicated in $84.6 \%$ of the children who had received the sequential treatment v. $48.8 \%$ of those on conventional treatment, the difference being highly significant $(p=0.02)$ (Table 4$)$.

Sequential therapy resulted in significantly higher eradication of $H$. pylori (84.6\%) than conventional therapy $(48.8 \%)$. Very few patients consented to a repeat endoscopy.

\section{Discussion}

There is a general consensus that more effective first-line treatment regimens for $H$. pylori are required to bring the eradication rate closer to $100 \%$. Standard triple therapy falls well short of this target, even when it is administered for 14 days. ${ }^{[14]}$

This study assessed both clinical improvement of the patient and H. pylori eradication after treatment. There was no difference in clinical improvement for both regimens, suggesting that resolution of symptoms after treatment did not necessarily mean eradication of the organism.

Slightly more than a third of the patients were in the 4 7-year age category, suggesting early acquisition of $H$. pylori and early inflammatory changes. This has been noted in studies from developing countries. ${ }^{[2]}$

With reference to $H$. pylori eradication, patients on the 10-day sequential therapy arm had a much higher $H$. pylori eradication rate than patients who received conventional treatment $(84.6 \%$ v. $48.8 \%$, respectively). There was a significant difference in eradication of $H$. pylori between the two regimens $(p=0.02)$. Previous studies have also shown that sequential therapy achieves better eradication rates than 7-day triple therapy. In a study by Zullo et al., ${ }^{[12]}$ eradication rates for the sequential therapy were $92 \%$ by intent to treat and $95 \%$ per protocol. A recent study from Turkey ${ }^{[15]}$ found that the eradication rate was higher for sequential therapy (93.7\%) than standard therapy (46.4\%). These findings are similar to the findings in our study. However, the eradication rates with sequential therapy in our study were still lower. This may be related to the more prevalent misuse of antibiotics in developing countries resulting in more resistant bacterial strains. ${ }^{[16]}$ The observed low eradication rates on the standard therapy regimen in this study, prompts re-evaluation of the currently used first-line treatment for H. pylori infection in Kenya.
Table 1. Characteristics of the study population $(N=71)$

\begin{tabular}{ll}
\hline Characteristic & $\boldsymbol{n}(\%)$ \\
\hline Gender & \\
Male & $38(53.5)$ \\
Female & $33(46.5)$ \\
Age (years) & \\
$0-3$ & $1(1.4)$ \\
$4-7$ & $26(36.6)$ \\
$8-11$ & $25(35.2)$ \\
$12-16$ & $19(26.8)$ \\
Regimen & \\
Conventional & $45(63.4)$ \\
Sequential & $26(36.6)$
\end{tabular}

Table 2. Demographic characteristics of the randomised groups

\begin{tabular}{lll}
\hline & \multicolumn{2}{c}{ Therapy, $\boldsymbol{n}(\%)$} \\
\cline { 2 - 3 } Characteristics & Conventional $(\boldsymbol{N}=\mathbf{4 5})$ & Sequential $(\mathbf{N = 2 6 )}$ \\
\hline Age (years) & $1(2.2)$ & $0(0)$ \\
$0-3$ & $17(37.8)$ & $9(34.6)$ \\
$4-7$ & $13(28.9)$ & $12(46.2)$ \\
$8-11$ & $14(31.1)$ & $5(19.2)$ \\
$12-16$ & & \\
Gender & $24(53.3)$ & $14(53.8)$ \\
Male & $21(46.7)$ & $12(46.2)$ \\
Female & &
\end{tabular}

Table 3. Clinical improvement in the participants

\begin{tabular}{llll}
\hline & \multicolumn{2}{c}{ Improvement, $\boldsymbol{n}$} & \\
\cline { 2 - 3 } Characteristic & Clinical & None & \\
\hline Gender & & & \\
$\quad$ Male & 32 & 6 & 0.19 \\
$\quad$ Female & 31 & 2 & \\
Age (years) & & & \\
$0-3$ & 1 & 0 & 0.79 \\
$4-7$ & 24 & 2 & \\
$8-11$ & 21 & 4 & \\
$12-16$ & 17 & 2 & \\
Regimen & & & \\
Conventional & 40 & 5 & 0.95 \\
Sequential & 23 & 3 &
\end{tabular}

Table 4. Eradication of H. pylori in the different treatment arms

\begin{tabular}{llll}
\hline & \multicolumn{2}{c}{ Therapy, $\boldsymbol{n} / \boldsymbol{N}(\mathbf{\%})$} & \multicolumn{1}{c}{$\boldsymbol{p}$-value } \\
\cline { 2 - 4 } Repeat test & Conventional $(\boldsymbol{N}=\mathbf{4 5})$ & $22 / 26(84.6)$ & 0.02 \\
\hline Stool H. pylori antigen negative & $22 / 45(48.8)$ & $2 / 3$ & - \\
Histology negative for H. pylori & $2 / 5$ & &
\end{tabular}


The superiority of sequential therapy over standard therapy may be related to a reduction in bacterial load with the initial phase of treatment with amoxicillin, which reduces the chances of developing mutations causing metronidazole and clarithromycin resistance. ${ }^{[17]}$ A notable finding was resolution of abdominal symptoms in almost $90 \%$ of patients in both treatment arms, despite a much lower eradication rate in the conventional treatment group. This may be explained by the antacid effect of the PPI causing symptomatic relief of dyspepsia. Unfortunately, we could not follow the patients for long enough to ascertain if their symptomatic relief was sustained. There were more patients in the 12 - 16-year age category in the sequential than the conventional group in the final analysis. Whether this made a difference in the eradication rates is difficult to predict, but it is expected that teenagers would be more likely to complain if symptoms persisted.

This study is the first in Kenya to assess the effectiveness of the sequential therapy in children in seeking to improve management of H. pylori infections.

\section{Study limitations}

A major setback was that not all patients attended their six-week review. The study protocol also entailed a repeat endoscopy and/ or stool $H$. pylori antigen testing at this six-week visit to assess eradication of $H$. pylori. Unfortunately, a substantial number of parents would not agree to repeat testing, especially endoscopy, as the children's symptoms had improved. After unblinding of the study, it was noted that most of those patients who were lost to follow-up were patients from the sequential treatment arm. Follow-up telephone calls to a few of the parents of these non-attendees confirmed that the patient was symptom free and that the parent did not see the need for a repeat visit and/or endoscopy. It is difficult to predict why more children in the sequential group did not attend the review v. the conventional group. It is known that compliance among patients who improve is poor compared with those who are still unwell while cultural practices may also play a role. ${ }^{[18,19]}$ It is tempting to suggest that because the children in the sequential group felt much better than their counterparts in the conventional group, they failed to come for their follow-up visit.

Based on findings from this study, there is a need to conduct a larger randomised, controlled trial in various settings to fully confirm our findings. However, we recommend that a sequential therapy regimen should replace the standard triple therapy treatment for $H$. pylori infection in children in Kenya.
Acknowledgements. We thank the Aga Khan University Hospital for a grant; the patients and staff of the Aga Khan University Hospital who participated in this study and Miss Wambui Njau for her input with the statistical analysis.

\section{References}

1. Vaira D, Gatta L, Ricci C, et al. Helicobacter pylori: Diseases, tests and treatment. Dig Liv Dis 2001;33(9):788-794. [http://dx.doi.org/10.1016/S1590-8658(01)80697-6]

2. Ozen A, Ertem D, Pehlivanoglu E. Natural history and symptomatology of Helicobacter pylori in childhood and factors determining the epidemiology of infection. J Pedriatr Gasroenterol Nutr 2006;42(4):398-394. [http://dx.doi.org/10.1097/01.mpg.0000215307.48169.7b]

3. Talley NJ, Vakil N. Guidelines for the management of dyspepsia. Am J Gastroenterol 2005;100(10):23242337. [http://dx.doi.org/10.1111/j.1572-0241.2005.00225.x]

4. Blaser MI, Chyou PH, Nomura A. Age at establishment of H. pylori infection and gastric carcinoma, Blaser MJ, Chyou PH, Nomura A. Age at establishment of H. pylori in
gastric ulcer and duodenal ulcer risk. Cancer Res 1995;55(3):562-565.

Agha A, Graham DY. Evidence-based examination of the African enigma in relation to Agha A, Graham DY. Evidence-based examination of the African enigma in relation to
Helicobacter pylori infection. Scand J Gastroenterol 2005;40(5):523-529. [http://dx.doi. Helicobacter pylori infection. Scand J Gastroenterol 2005;40(5):523-529. [http://dx.do

org/10.1080/00365520510012280]
6. Feldman RA. Epidemiologic Observations and Open Questions about Disease and Infection Caused by Helicobacter Pylori. In: Achtman M, Suerbaum S, eds. Helicobacter pylori: Molecular and Cellular Biology. Wymondham, UK: Horizon Scientific Press, 2001:29-51.

7. Lam S, Talley N. Report of the 1997 Asia Pacific Consensus Conference on the managemen of Helicobacter pylori infection. J Gastroenterol Hepatol 1998;13(1):1-12. [http://dx.doi. org/10.1111/j.1440-1746.1998.tb00537.x

8. Gerrits MM, van Vliet AH, Kuipers EJ, et al. Helicobacter pylori and antimicrobial resistance Molecular mechanisms and clinical implications. Lancet Infect Dis 2006;6(11):699-709. [http://dx.doi org/10.1016/S1473-3099(06)70627-2]

9. Tanih NF, Dube C, Green E, et al. An African perspective on Helicobacter pylori: Prevalence of human infection, drug resistance, and alternative approaches to treatment. Ann Trop Med Parasitol 2009;103(3):189-204. [http://dx.doi.org/10.1179/136485909X398311]

10. Malfertheiner P, Megraud F, O'Morain C, et al. Current concepts in the management of $\mathrm{H}$. pylor Malfertheiner P, Megraud F, O'Morain C, et al. Current concepts in the management of H. pylori
infection: The Maastricht III Consensus Report. Gut 2007;56(6):772-781. [http://dx.doi.org/10.1136/ gut.2006.101634]

11. Laheij RJ, Rossum LG, Jansen JB, et al. Evaluation of treatment regimens to cure Helicobacter pylori infection - A meta-analysis. Aliment Pharmacol Ther 1999(7);13:857-864. [http://dx.doi.org/10.1046/ j.1365-2036.1999.00542.x

12. Zullo A, Vaira D, Vakil N, et al. High eradication rates of Helicobacter pylori with a new sequential treatment. Aliment Pharmacol Ther 2003;17(5):719-726. [http://dx.doi.org/10.1046/j.13652036.2003.01461.x]

13. Francavilla R, Lionetti E, Castellaneta SP, et al. Improved efficacy of 10 day sequential treatment for Helicobacter pylori eradication in children: A randomized trial. Gastroenterology 2005;129(5):14141419. [http://dx.doi.org/10.1053/j.gastro.2005.09.007]

14. Calvet X, Garcia N, Lopez T, et al. A meta-analysis of short versus long therapy with a proton pump inhibitor, clarithromycin and either metronidazole or amoxycillin for treating Helicobacter pylori infection. Aliment Pharmacol Ther 2000;14(5):603-609. [http://dx.doi.org/10.1046/j.13652036.2000.00744.x]

15. Erdur, B, Ozturk, Y, Gurbuz ED, et al. Comparison of sequential and standard therapy for H. pylor Erdur, B, Ozturk, Y, Gurbuz ED, et al. Comparison of sequential and standard therapy for H. pylori
eradication in children and investigation of clarithromycin resistance. I Pediatr Gastroenterol Nutr 2012;55(5):530-533. [http://dx.doi.org/10.1097/MPG.0b013e3182575f9c]

16. Kimanga AN. A situational analysis of antimicrobial drug resistance in Africa: Are we losing the battle? Ethiop J Health Sci 2012;22(2):135-143

17. Roberts MC. Resistance to macrolide, lincosamide, streptogramin, ketolide, and oxazolidinon antibiotics. Mol Biotechnol 2004;28(1):47-62. [http://dx.doi.org/10.1385/MB:28:1:47]

18. Sengayi M, Dwane N, Marinda E, Sipambo N, Fairlie L, Moultrie H. Predictors of loss to follow-up among children in the first and second years of antiretroviral treatment in Johannesburg, South Africa. Glob Health Action 2013;6:19248. [http://dx.doi.org/10.3402/gha.v6i0.19248]

19. Alvarez-Uria G, Naik PK, Pakam R, Midde M. Factors associated with attrition, mortality, and loss to follow up after antiretroviral therapy initiation: Data from an HIV cohort study in India. Glob Healt Action 2013;6:21682. [http://dx.doi.org/10.3402/gha.v6i0.21682]

Accepted 16 October 2013. 